\title{
CONVENÇÃO
}

\section{INTERAMERICANA SOBRE A} PROTEÇÃO DOS DIREITOS HUMANOS DOS IDOSOS: ANÁLISE DA TUTELA DA SAÚDE MENTAL DOS IDOSOS E A INTERFACE COM OS DIREITOS DA PERSONALIDADE

\author{
INTER AMERICAN CONVENTION ON HUMAN RIGHTS \\ PROTECTION OF ELDERLY PEOPLE: \\ ANALYSIS OF THE ELDERLY MENTAL HEALTH TUTELAGE \\ AND THE INTERFACE WITH PERSONALITY RIGHTS
}

\author{
DANIELA MENENGoti GONÇALVES RIBEIRO ${ }^{1}$ \\ DENISE MARIA LOPES ZANUTTO ${ }^{2}$ \\ JOSÉ CARLOS ALVES NASCIMENTO ${ }^{3}$
}

\section{RESUMO}

O presente artigo analisa o aumento do envelhecimento da população mundial e os novos desafios que advém desse crescimento; enfatiza a saúde da pessoa idosa, em especial, a sua integridade física, mental e social e resgata a preocupação da Organização Mundial da Saúde e da Organização dos Estados Americanos para que os países membros adotem políticas públicas adequadas à saúde da pessoa idosa. Objetiva-se, por meio de uma visão panorâmica acerca do tema, partindo do Estatuto do Idoso e da Convenção Interamericana de Proteção aos Idosos, de 2015, examinar a tutela da saúde psicofísica da pessoa idosa, a qual efetiva os seus direitos da personalidade. Esta pesquisa emprega como método de abordagem o dedutivo, promove por meio da revisão de literatura especializada, descritiva e exploratória uma reflexão à comunidade jurídica acadêmica sobre a temática. Conclui-se que há a necessidade latente de implementação de

1 Professora do Programa de Mestrado e Doutorado em Direito da UNICESUMAR. Pesquisadora do Instituto Cesumar de Ciência, Tecnologia e Inovação (ICETI). Doutora em Direito-Relações Econômicas Internacionais pela Pontifícia Universidade Católica de São Paulo (PUC/SP) com período de pesquisa (doutorado sanduíche) na Université Paris 1 - Panthéon-Sorbonne, França. ORCID iD: http://orcid.org/0000-0001-7621-8899. E-mail: daniela.menengoti@gmail.com.

2 Mestranda em Ciências Jurídicas pela (UNICESUMAR) Universidade Cesumar. ORCID iD: http://orcid.org/0000-0003-16977652. E-mail: zanuttodenise@gmail.com.

3 Mestrando em Ciências Jurídicas pela Universidade Cesumar (UNICESUMAR). Especialista em Direito do Estado pela Universidade Estadual de Londrina. Procurador municipal. Advogado.Mestrando em Ciências Jurídicas pela Universidade Cesuma (UNICESUMAR) - Especialista em Direito do Estado pela Universidade Estadual de Londrina - Procurador municipal - Advogado. ORCID iD: http://orcid.org/0000-0002-5110-856X. E-mail: jcanascimento44@gmail.com. 
políticas públicas brasileiras adequadas à saúde dos sexagenários, respeitando os direitos da personalidade do idoso, favorecendo a sua dignidade, principalmente, no que tange a sua integridade e saúde mental.

PALAVRAS-CHAVE: Convenção Interamericana sobre a Proteção dos Direitos Humanos dos Idosos. Estatuto do Idoso. Direitos da Personalidade. Saúde Mental.

\section{ABSTRACT}

The present article analyzes the increase in the aging population around the world and the new challenges created by this increase, emphasizing the health of an elderly person, in special his/her physical, mental and social integrity. It brings forth the World Health Organization and the Organization of American States preoccupation in making member countries implement adequate public policies regarding the health of elderly people. The objective is to examine the tutelage of the psychophysical health of the elderly through a panoramic view of the theme, based on the Statute of the Elderly and the Inter American Convention on Protecting the Human Rights of the Older Person, which guarantees their personality rights. This research adopts the deductive approach and intends, through a specialized, descriptive and exploratory literature review, to promote a reflection on the theme by the academic legal community. Results from this study show the latent need for implementing Brazilian public policies adequate to the health of people over 60 years of age, respecting their personality rights and favoring their dignity, mainly in regards to their integrity and mental health.

KEYWORDS: Inter American Convention on Protecting the Human Rights of Older Persons. Statute of the Elderly. Personality Rights. Mental Health.

\section{INTRODUÇÃO}

A sociedade pós-moderna tem apresentado um novo retrato populacional com o aumento dos idosos, por consequência, novos desafios sociais e jurídicos são suscitados e merecem a atenção dos operadores do direito. Destarte, o presente estudo é relevante para a pesquisa científica, uma vez que lança um novo olhar acerca da saúde do idoso.

Como problemática, analisa-se a importância do Estatuto do Idoso de 2003, doravante, denominado Estatuto, e da Convenção Interamericana de Proteção aos Idosos de 2015, a partir de agora, designada Convenção, no que esses dois diplomas legais tutelam a saúde psicofísica da pessoa idosa efetivando os seus direitos da personalidade. Esses, remetem a valores imprescindíveis como a vida, a integridade psicofísica e dignidade.

O presente artigo contando com a introdução, está dividido em mais cinco partes. 0 segundo tópico versa sobre novo retrato da população mundial e o aumento do envelhecimento. 0 terceiro, enfoca sobre a tutela da população idosa brasileira e a contribuição do Estatuto. 0 quarto, analisa os objetivos da Convenção enfatizando a saúde da pessoa idosa. Finalmente, o quinto, discorre sobre a saúde dos idosos e as políticas públicas brasileiras frente à conclamação da Organização Mundial da Saúde, doravante, nomeada OMS.

A pesquisa trata do lapso temporal compreendido a partir de alguns marcos internacionais cruciais relacionados à importância da saúde da pessoa idosa. Esses, são retratados desde a Assembleia Mundial sobre o Envelhecimento de 1982, resgatando o Princípio das Nações Unidas em Favor das Pessoas Idosas de 1991 e a Segunda Assembleia Mundial das Nações Unidas sobre o Envelhecimento de 2002. Os marcos nacionais referem-se ao perí- 
odo de análise situada entre o Estatuto de 2003, passando pela Convenção de 2015, a qual o Brasil se comprometeu, até a lei n 13.819 de 2019 que instituiu a Política Nacional de Prevenção da Automutilação e do Suicídio. Busca-se, nesses documentos, dispositivos legais que corroborem com a tutela da saúde psicofísica dos idosos brasileiros.

A presente pesquisa emprega como método de abordagem, o dedutivo. Para obter uma visão panorâmica acerca do tema, realiza-se uma ampla revisão de literatura especializada. As fontes empregadas foram o Estatuto; a Convenção; revistas jurídicas; jornais; livros; jurisprudência; artigos científicos; sites especializados de sindicato de hospitais, de psicologia, de enfermagem; sites jurídicos nacionais e internacionais que corroboraram com a temática. Firma-se, de tal modo, um conjunto de material dinâmico, quantitativo e qualitativo.

Para tanto, resgata-se estudo elaborado pela OMS, através do qual se constata o aumento de casos de depressão entre as pessoas idosas no mundo. Os resultados fazem as instituições internacionais como a OMS conclamar por mudanças aos países membros, incluindo o Brasil, exigindo novas alternativas para esses desafios. Por seu turno, a Organização dos Estados Americanos, daqui em diante designada (OEA), logra êxito na elaboração da Convenção, como um documento que vincula os Estados-membros. Ela compromete a maior parte dos países americanos, inclusive o Brasil, no engajamento de diversos direitos dos idosos, inclusive no que tange ao direito à saúde psicofísica desse grupo.

Na sequência, foca-se na legislação doméstica, nos dispositivos do Estatuto, da Constituição Federal de 1988 e dos direitos de personalidade no que se refere ao tema. Verifica-se na pesquisa que o aumento populacional dos idosos brasileiros e o crescimento de determinados problemas que envolvem a saúde desse grupo merecem especial atenção. Observou-se que muitas causas de depressão entre os sexagenários são ocasionadas pela falta de condições econômicas, discriminação, abandono, violência e ausência de um espaço adequado de convivência para muitos deles. Diante de tais constatações, conclui-se que o Brasil necessita de implementar políticas públicas efetivas à saúde integral do idoso, visando a promoção do seu bem-estar psicofísico e social.

\section{NOVO RETRATO DA POPULAÇÃO MUNDIAL: O AUMENTO DO ENVELHECIMENTO}

Hodiernamente, observa-se uma imensa transformação no processo demográfico mundial com o aumento da população idosa e, em contrapartida, uma acentuada diminuição da taxa de natalidade. Essa nova configuração ocorre em vários países e no Brasil não é distinto. Tal configuração é constatada através de dados divulgados pela Organização das Nações Unidas (ONU) e pela OMS.

A ONU adverte que o número de sexagenários deverá duplicar entre os anos de 2007 a 2050 e a perspectiva é de que esse número atual triplique, aproximando-se da média de dois bilhões. Não é por acaso que a ONU, OMS e o UNFPA têm apresentado diretrizes e foco em políticas públicas diante desse novo quadro demográfico. O número de pessoas idosas a partir da faixa etária de 60 anos, em todo o mundo, está estimado para chegar em 1,4 bilhão 
em 2030, e aproximadamente a 2,1 bilhões em 2050 (ORGANIZAÇÃO DAS NAÇÕES UNIDAS, 2019).

Devido ao aumento da população idosa no mundo, expandiu-se o embate sobre os direitos desse grupo. Em 1982, a Assembleia Mundial sobre o Envelhecimento aprovou o Plano de Ação Internacional de Viena sobre o Envelhecimento. Esse Plano de Ação "contém 62 recomendações, muitas das quais têm uma relevância direta para o Pacto Internacional dos Direitos Econômicos, Sociais e Culturais que é a base da política para a pessoa idosa, no plano internacional" (ROBINSON, 2019).

Especificamente em 1991, a Assembleia Geral destacou o documento denominado "Princípio das Nações Unidas em Favor das Pessoas Idosas e enumerou 18 direitos das pessoas idosas em relação à independência, participação, cuidado, autorrealização e dignidade" (ORGANIZAÇÃO DAS NAÇÕES UNIDAS, 2019). Dando continuidade à referida política, no ano seguinte, a Conferência Internacional sobre o Envelhecimento reuniu-se para dar seguimento ao Plano de Ação, adotando a Proclamação do Envelhecimento. Seguindo a recomendação da Conferência, a Assembleia Geral da ONU, em 1999, declarou o Ano Internacional do Idoso (ORGANIZAÇÃO DAS NAÇÕES UNIDAS, 2019).

Em 2002, ocorreu a Segunda Assembleia Mundial das Nações Unidas sobre o EnveIhecimento, a qual fora realizada na cidade de Madrid, na Espanha e objetivou desenvolver uma política internacional para o envelhecimento no século XXI. A referida Assembleia adotou uma declaração política, que ficou conhecida como Plano de Ação Internacional sobre o Envelhecimento de Madrid (2002) e suas recomendações específicas para ação foram as seguintes: prioridade às pessoas mais velhas, desenvolvimento objetivando melhorar a saúde, bem-estar na velhice, assegurando habilitação e ambientes de apoio (ORGANIZAÇÃO DAS NAÇÕES UNIDAS, 2019).

O Brasil, conforme divulgado no Jornal da Universidade de São Paulo, caminha para se tornar a quinta maior população de pessoas idosas no mundo e já contabiliza, aproximadamente, 27 milhões de pessoas com faixa etária acima dos 60 anos. Em 2050, calcula-se que esse número estará próximo de 64 milhões, representando quase $30 \%$ da população brasileira (UNIVERSIDADE DE SÃO PAULO, 2018).

Ante ao cenário apresentado, faz-se necessário que a sociedade brasileira repense políticas públicas que levem em consideração a tendência do envelhecimento da população nacional e que atendam às necessidades dos idosos, respeitando a sua dignidade. Tal fato constitui-se um novo desafio à sociedade pós-moderna. O Brasil também necessita de buscar a implementação de políticas públicas adequadas à terceira idade para responder a essas novas exigências.

\section{A TUTELA DA POPULAÇÁO IDOSA BRASILEIRA: A CONTRIBUIÇÁOO DO ESTATUTO DO IDOSO}

Após cinco anos de tramitação no Congresso Nacional, foi instituído o Estatuto que regulamenta os direitos dos idosos brasileiros. Ele funciona como instrumento jurídico pri- 
mordial para trazer à tônica a dignidade que merece a terceira idade. Nesse sentido, deve ser examinado a fim de visualizar, nesse importante instumento, a tutela da saúde integral dos sexagenários.

No Brasil, o idoso é protegido pela Constituição Federal de 1988 no capítulo que trata da família, mais especificamente no artigo 230, o qual prevê que a família, a sociedade e o Estado têm o dever de amparar as pessoas idosas, assegurando sua participação na comunidade, defendendo sua dignidade e bem-estar e garantindo-lhes o direito à vida. Ainda no artigo 229, do mesmo diploma está instituído o dever dos filhos maiores, em assistir os pais e cuidar deles na velhice, na carência e na enfermidade (BRASIL, 1988).

O Estatuto, cujo projeto nasceu com a organização e a mobilização dos aposentados, pensionistas e idosos, tramitou por anos no Congresso Nacional, foi aprovado em setembro de 2003 e instituído pela lei $n^{\circ} 10.741$ de 2003. Esse Estatuto é destinado a regular os direitos assegurados às pessoas idosas e dispõe de normas e diretrizes para a formulação e a execução de políticas públicas e de serviços destinados ao idoso. Além da sua força normativa, o Estatuto ainda goza do prestígio que conquistou perante a sociedade, e, se tornou um marco na história da proteção à velhice. Resultando em mudanças significativas das relações com o idoso e aos espaços sociais destinados a esses (BRASIL, 2003).

O referido diploma legal é, ainda, entendido como um "dispositivo de Estado e também como parte de um conjunto de práticas discursivas que instaura a velhice como categoria de pensamento e significação a partir de imagens geradas, por meio das quais a realidade passa a ser apreendida e modelada" (JUSTO; ROZENDO, 2010). Vale lembrar que, conforme disposto no seu artigo $1^{\circ}$, é considerada idosa a pessoa com idade igual ou superior a 60 (sessenta) anos, sendo essa população idosa protegida pelo Estatuto (BRASIL, 2003).

Apesar da Constituição Federal de 1988 já prevê o rol de direitos fundamentais, em seu artigo $5^{\circ}$, o Estatuto, objetivando dá maior ênfase, reproduziu tal norma constitucional em seu artigo $2^{\circ}$, o qual dispõe que o idoso goza de todos os direitos fundamentais inerentes à pessoa humana. Assegurando-Ihe por lei todas as oportunidades e facilidades para preservação de sua saúde física e mental, bem como ao seu aperfeiçoamento moral, intelectual, espiritual e social, em condições de liberdade e dignidade (BRASIL, 2003).

Outrossim, objetivando a preservação da saúde e da integridade física e psíquica, bem como, o bem-estar do idoso, o artigo $4^{\circ}$ do Estatuto, estabeleceu a sua proteção contra qualquer tipo de negligência, discriminação, violência, crueldade ou opressão. Prevendo, ainda, que todo atentado aos seus direitos, por ação ou omissão, será punido na forma da lei. Por outro lado, a lei dispensou tratamento diferenciado ao idoso, garantindo a este, dentre outros direitos, o atendimento prioritário em órgãos públicos e privados prestadores de serviços à população; preferência na formulação e na execução de políticas sociais públicas específicas; priorização do atendimento do idoso por sua própria família, em detrimento do atendimento asilar, exceto dos que não a possuam ou careçam de condições de manutenção da própria sobrevivência; garantia de acesso à rede de serviços de saúde e de assistência social locais, etc. (BRASIL, 2003).

O Estatuto assegurou igualmente a prioridade na tramitação dos processos e procedimentos e na execução dos atos e diligências judiciais em que figure como parte ou interveniente a pessoa considerada idosa por essa lei, em qualquer instância ou Tribunal. 
Ressalte-se, ainda, que em virtude do aumento da expectativa de vida do brasileiro, em 2017 foi editada a lei $n^{\circ} 13.466$ garantindo a prioridade diferenciada aos idosos maiores de 80 (oitenta) anos, ou seja, a prioridade da prioridade (BRASIL, 2003).

Também há previsão no Estatuto de que o envelhecimento é um direito personalíssimo e a sua proteção um direito social, e que é obrigação do Estado, garantir à pessoa idosa, a proteção à vida e à saúde, mediante efetivação de políticas sociais públicas que permitam um envelhecimento saudável e em condições de dignidade, e, ainda, de assegurar à pessoa idosa a liberdade, o respeito e a dignidade, como pessoa humana e sujeito de direitos civis, políticos, individuais e sociais, garantidos na Constituição e nas leis (BRASIL, 2003).

No que tange ao direito à saúde, há disponível um capítulo inteiro para tratar do tema. O artigo assegura a atenção integral à saúde do idoso, por intermédio do Sistema Único de Saúde, SUS. Garantindo-Ihe o acesso universal e igualitário, em conjunto articulado e contínuo das ações e serviços, para a prevenção, promoção, proteção e recuperação da saúde, incluindo, a atenção especial às doenças que afetam preferencialmente os idosos. Ainda determinou que incumbe ao Poder Público o fornecimento gratuito de medicamentos aos idosos, especialmente os de uso continuado; assim como próteses, órteses e outros recursos relativos ao tratamento, habilitação ou reabilitação (BRASIL, 2003).

Dentre os diversos direitos relacionados à saúde do idoso, o Estatuto previu que os idosos portadores de deficiência ou com limitação incapacitante terão atendimento especializado. Ademais, incluiu a vedação da exigência do comparecimento do idoso enfermo perante os órgãos públicos, sendo assegurado ao idoso, nessas condições elencadas, o atendimento domiciliar pela perícia médica do Instituto Nacional do Seguro Social - INSS, pelo serviço público de saúde ou pelo serviço privado de saúde, contratado ou conveniado, que integre - SUS, para expedição de laudo de saúde necessário ao exercício de seus direitos sociais e para obtenção de isenção tributária (BRASIL, 2003).

Por último, o Estatuto assegurou ao idoso internado ou em observação o direito a acompanhante. Deve o órgão de saúde proporcionar as condições adequadas para a sua permanência em tempo integral, segundo o critério médico, cabendo ao profissional de saúde responsável pelo tratamento conceder autorização para o acompanhamento do idoso ou, no caso de impossibilidade, justificá-la por escrito (BRASIL, 2003).

O Relatório Mundial sobre Violência e Saúde de 2002 define a violência contra a pessoa idosa como qualquer ato, único, repetitivo, omissão, que ocorra em qualquer relação supostamente de confiança, que cause dano ou incômodo a ela (ORGANIZAÇÃO MUNDIAL DA SAÚDE, 2002). A violência contra o idoso, por sua vez, também é conceituada, pelo Estatuto, como aquela praticada contra o idoso por qualquer ação ou omissão em local público ou privado que lhe cause morte, dano ou sofrimento físico ou psicológico (BRASIL, 2003).

Com relação à proteção contra a violência praticada contra o idoso, o Estatuto determina que, em casos de suspeita ou confirmação, serão objeto de notificação compulsória pelos serviços de saúde públicos e privados à autoridade sanitária, bem como serão, obrigatoriamente, comunicados por eles a quaisquer dos seguintes órgãos: I - autoridade policial; II - Ministério Público; III - Conselho Municipal do Idoso; IV - Conselho Estadual do Idoso e V - Conselho Nacional do Idoso (BRASIL, 2003). 
Objetivando a proteção do idoso contra o abandono, o Estatuto anteviu, ainda, que a assistência social aos idosos será prestada, de forma articulada, conforme os princípios e diretrizes previstos na Lei Orgânica da Assistência Social (LOAS), no Sistema Único de Saúde e demais normas pertinentes. Augurando, também, o pagamento de um benefício mensal no valor de um salário mínimo aos idosos, que a partir de sessenta e cinco anos, que não possuam meios para prover sua subsistência, nem de tê-la provida por sua família (BRASIL, 2003).

Finalmente, visando coibir toda forma de violência contra o idoso, o Estatuto elencou uma série de condutas que passaram a ser consideradas crimes, tais como: discriminar pessoa idosa, impedindo ou dificultando seu acesso à operações bancárias, aos meios de transporte, ao direito de contratar ou por qualquer outro meio ou instrumento indispensável ao exercício da cidadania, por motivo de idade; deixar de prestar assistência ao idoso, quando possível fazê-lo sem risco pessoal, em situação de iminente perigo, ou recusar, retardar ou dificultar sua assistência à saúde, sem justa causa, ou não pedir, nesses casos, o socorro de autoridade pública, etc. (BRASIL, 2003).

O Estatuto alterou o artigo 244 do Código Penal de 1940 para constar como crime de abandono material a conduta de deixar, sem justa causa, de prover a subsistência do cônjuge, ou de filho menor de dezoito anos ou inapto para o trabalho, ou de ascendente inválido ou maior de sessenta anos. Não lhes proporcionando os recursos necessários ou faltando ao pagamento de pensão alimentícia judicialmente acordada, fixada ou majorada. E ainda, deixar, sem justa causa, de socorrer descendente ou ascendente, gravemente enfermo (BRASIL, 2003).

Os Tribunais já estão aplicando o crime de abandono material praticado contra o idoso, nos termos do artigo 244 do Código Penal acrescentado pelo Estatuto, conforme decidiu o Tribunal de Justiça do Rio de Janeiro em julgamento de recurso de apelação criminal $n^{\circ}$ 0201897.91.2011.8.19.0001, da 38 ${ }^{\text {a }}$ Vara Criminal. Na ocasião, aquela Corte determinou a aplicação da pena prevista no Estatuto e ainda majorou a pena com base na agravante prevista para os crime praticados contra a pessoa idosa (RIO DE JANEIRO, 2013).

Apesar da preocupação do legislador em proteger juridicamente o idoso, o que se presencia atualmente, em diversos lares do Brasil, é o abandono, violência contra o idoso e a falta de políticas públicas adequadas. Algumas vezes, constata-se que os principais perpetradores dos maus tratos contra os idosos são seus próprios familiares e vizinhos, configurando assim, um alto índice de agressores dentro das famílias. Conclusão que decorre no enfraquecimento do vínculo de solidariedade e afetividade entre seus membros, sendo, a sobrecarga do cuidador, a situação desencadeante desses abusos (BRASIL, 2017).

Segundo a Secretaria de Direitos Humanos, do Ministério da Mulher, da Família e dos Direitos Humanos, ocorre um aumento de casos de abandono e violência contra os idosos. Em 2011, morreram 24.669 pessoas idosas por acidentes e violências no país, significando, por dia, 68 óbitos. Os homens foram 15.342 (62,2\%) e, as mulheres, $9.325(37,8 \%)$. Somente em 2017, a Secretaria de Direitos Humanos registrou mais de 33 mil casos de agressões a pessoas acima de 60 anos (BRASIL, 2017). Observa-se que os números são alarmantes, mormente, considerando o aumento do envelhecimento entre a população. A violência cometida contra o indivíduo idoso é considerada uma violação aos direitos humanos, consistindo em 
uma das causas mais relevantes de lesões, doenças, perda da produtividade, isolamento, depressão e até suicídio.

As políticas públicas de saúde mental no Brasil, embora tenham alcançado avanço, em relação às propostas de tratamento de transtornos mentais, ainda carecem de atenção por parte dos gestores e autoridades públicas para garantir o direito ao tratamento adequado e digno aos pacientes com depressão ou algum distúrbio mental. (ALENCAR; RAIOL, 2020). Por isso, há urgência na articulação entre família, sociedade civil e o poder público para minimizar o índice de automutilações e de suicídios. Necessário se faz uma política pública com caráter multissetorial e integrador, objetivada na prevenção, apta para identificar em tempo hábil aqueles que desenvolvem a ideação-suicida, antes da tentativa se consumar, e assim, reduzir os números de suicídios (SANTOS; SCHMIDT, 2019).

Essa tendência ao suícidio entre a população idosa também é verificada no Brasil conforme estudo realizado pela professora da Escola Nacional de Saúde Pública da Fiocruz-RJ, a socióloga Maria Cecília Minayo. O estudo fora realizado entre os anos de 2010 a 2012 e publicado no Jornal Diário da Manhã, com o título "Violência contra o idoso provoca desejo de suicídio" (DIÁRIO DA MANHÃ, 2016).

No referido estudo, a professora esclarece que a condução da pessoa ao suicídio nunca tem uma só causa e que a influência da história de vida da pessoa, incluindo o sofrimento, a violência, o isolamento e muitas vezes maus-tratos, levam-na a praticar tal ato. "E aí quando a pessoa chega à última idade sente que sua vida não tem mais sentido". (MINAYO, 2016).

Nesse viés, é fundamental que a sociedade preste mais atenção à vulnerabilidade da pessoa idosa, conforme preceitua o Estatuto. Voltar a atenção para sua saúde de forma integral, particularmente, ao que se refere ao seu aspecto mental e emocional, ajudará a minimizar os números de depressão e consequentemente diminuirá os casos de suicídio entre as pessoas idosas. Os direitos da personalidade, conceituados como aqueles inerentes à própria pessoa humana, constituem prerrogativas ou faculdades que permitem aos indivíduos o desenvolvimento de suas aptidões, energias físicas e psíquicas. Essas devem ser respeitadas no cotidiano da população idosa, a qual, deve viver com dignidade.

\section{ANÁLISE DOS OBJETIVOS DA CONVENÇÃO INTERAMERICANA SOBRE A PROTEÇÁO DOS DIREITOS HUMANOS DOS IDOSOS: FOCO NA SAÚDE DA PESSOA IDOSA}

Diante do cenário de envelhecimento da população mundial, o Brasil segue a mesma tendência e, por isso, torna-se crucial proteger os direitos fundamentais dos idosos brasileiros. Inclusive, conforme já salientado, essa população tem ganhado novo olhar perante os organismos internacionais como a OMS e OEA. Os países americanos também apresentam perfil semelhante em relação ao crescimento desse grupo específico. 
Com a finalidade de apresentar respostas a essa nova realidade, as nações da América negociaram e aprovaram, em 15 de junho de 2015, a Convenção Interamericana sobre a Proteção dos Direitos Humanos dos Idosos, concluída no âmbito da Organização dos Estados Americanos (OEA) em 2015, celebrada em Washington. Esse documento juridicamente vincula os Estados que se comprometeram sobre os direitos das pessoas idosas. Dentre esses, está incluso, o Brasil que o assinou (ORGANIZAÇÃO DOS ESTADOS AMERICANOS, 2015). Nesse sentido, destaca-se que, "os Estados modernos não se limitam a garantir os direitos mínimos aos indivíduos, mas também atuam na promoção de implementação dos direitos fundamentais individuais, sociais e coletivos" (REMEDIO; FARIA, 2019, p. 723).

A Convenção foi celebrada com o objetivo de promover, proteger e assegurar o reconhecimento, gozo e exercício, em condições de igualdade, de todos os direitos humanos e liberdades fundamentais do idoso. 0 referido documento reconhece as pessoas idosas como sujeitos de direitos, garantindo a sua inclusão, integração e participação na sociedade, em linha com as disposições do Estatuto, instituído no Brasil, pela lei nº 10.741 de 2003 (BRASIL, 2017).

O texto foi subscrito pelos Estados que fazem parte da OEA fundamentado na necessidade de se instituir um documento regional, juridicamente vinculante, que protegesse os direitos humanos dos idosos e fomentasse um envelhecimento ativo em todos os âmbitos. Todavia, houve o cuidado de se realizar um instrumento que não limitasse os direitos já adquiridos pela população idosa em suas nações (ORGANIZAÇÃO DOS ESTADOS AMERICANOS, 2015).

O Projeto de Decreto Legislativo nº 863 de 2017, no âmbito da Câmara Federal, aprovou o texto da Convenção Interamericana sobre a Proteção dos Direitos Humanos dos Idosos com 41 (quarenta e um) artigos. 0 texto é dividido em 7 (sete) capítulos e contém, ainda, ao final, notas de rodapé a respeito do conteúdo e dos limites quanto aos compromissos assumidos pelos Estados Partes (BRASIL, 2017).

O Capítulo I da Convenção, de 2015, delimita os objetivos, âmbito de aplicação e definições dos termos utilizados no texto convencional. Entretanto, o principal objetivo da Convenção é "promover, proteger, assegurar o reconhecimento e o pleno gozo e exercício, em condições de igualdade, de todos os direitos humanos, liberdades fundamentais do idoso, a fim de contribuir para sua plena inclusão, integração e participação na sociedade." Destaque-se, porém, que o disposto neste diploma legal "não deve ser interpretado como uma limitação a direitos ou benefícios mais amplos ou adicionais reconhecidos pelo direito internacional ou pelas legislações internas dos Estados Partes em favor do idoso." (BRASIL, 2017).

O Capítulo II apresenta os princípios gerais aplicáveis à Convenção. Tais princípios estão listados e apresentam 15 (quinze) direitos e prerrogativas que favorecem as pessoas idosas. São eles: a promoção e defesa dos direitos humanos e liberdades fundamentais do idoso; a valorização do idoso, seu papel na sociedade e sua contribuição ao desenvolvimento; a dignidade, independência, protagonismo e sua autonomia. Enfatiza a igualdade e não discriminação do idoso, sua participação, integração e inclusão efetiva na sociedade; direito ao bem-estar e cuidado, a auto realização; a solidariedade e o fortalecimento da proteção familiar. Frise-se ainda que deve ocorrer a participação da família, da comunidade, do Estado na integração ativa e produtiva do idoso, observando a legislação interna (BRASIL, 2017). 
O Capítulo III elenca os deveres gerais dos Estados Partes, que se comprometem a salvaguardar os direitos humanos e as liberdades fundamentais do idoso, sem nenhum tipo de discriminação, conforme estabelecido nos termos do artigo $4^{\circ}$. Há o destaque para as medidas direcionadas a prevenir, punir e erradicar práticas, tais como, isolamento, abandono, sujeição física prolongada, aglomeração, expulsão da comunidade, negação de nutrição, infantilização, tratamentos médicos inadequados. Também deve-se erradicar práticas que constituam maus-tratos ou penas cruéis, desumanas ou degradantes que atentem contra a segurança e integridade da pessoa idosa (BRASIL, 2017).

O Capítulo IV abrange os principais direitos referentes às pessoas idosas, que serão protegidas, mas cuja responsabilidade, quanto à garantia e observância, é atribuição dos Estados Partes. Os artigos 5 a 31, do referido capítulo, elencam esses direitos, a saber: igualdade e não discriminação por razões de idade; direito à vida e à dignidade na velhice; direito à independência e à autonomia; direito à segurança e a uma vida sem nenhum tipo de violência; direito a não ser submetido à tortura nem a penas ou tratamentos cruéis, desumanos ou degradantes; direito a manifestar consentimento livre e informado no âmbito da saúde; direitos do idoso que recebe serviços de cuidado de longo prazo; direito à liberdade pessoal; direito à liberdade de expressão e opinião e ao acesso à informação; direito à nacionalidade e à liberdade de circulação; direito à privacidade e à intimidade; direito à seguridade social; direito ao trabalho; direito à saúde; direito à educação; direito à cultura; direito à recreação, ao lazer e ao esporte; direito à propriedade; direito à moradia; direito a um meio ambiente saudável; direito à acessibilidade e à mobilidade pessoal; direitos políticos; direito de reunião e de associação; direito ao amparo em situações de risco e emergências humanitárias; direito a igual reconhecimento como pessoa perante a lei e o direito de acesso à justiça (BRASIL, 2017).

A Convenção, em seu Capítulo V, estabelece norma pela qual os Estados Partes comprometem-se a promover uma tomada de consciência sobre a condição da pessoa idosa, por meio de medidas que fomentem a divulgação e capacitação progressiva de toda a sociedade sobre a Convenção; gerem uma atitude positiva em relação à velhice; sensibilizem a sociedade e estimulem a participação desta e de suas organizações na formulação e estruturação de programas voltados à pessoa idosa; incluam o tema do envelhecimento ativo nos programas de ensino e na agenda acadêmica; bem como promovam o reconhecimento e a contribuição da experiência da pessoa idosa para toda a sociedade (BRASIL, 2017).

O Capítulo VI trata sobre o mecanismo de acompanhamento da Convenção constituído por uma Conferência de Estados Partes e por um Comitê de Peritos, bem como, com um Sistema de Petições Individuais, que prevê a possibilidade de apresentação de petições, que contenham denúncias ou queixas à Comissão Interamericana de Direitos Humanos (BRASIL, 2017). Já o Capítulo VII trata de questões relativas aos procedimentos de assinatura, ratificação, adesão, entrada em vigor, depósito, denúncia, formulação de reservas e apresentação de emendas ao texto constitucional (BRASIL, 2017).

Em suma, ao analisar o texto da Convenção, constata-se que, a iniciativa do referido documento é salutar e imprescindível, uma vez que, o envelhecimento populacional, no Brasil, exige políticas públicas, que assegurem os direitos da população idosa. Observa-se que, se por um lado, o Estado Parte tem o dever de tutelar ou proteger os direitos fundamentais por meio de normas, da atividade administrativa e da jurisdição, daí decorrendo as tutelas 
normativa, administrativa e jurisdicional dos direitos, por outra parte, há direitos que também são tutelados por uma ordem supranacional, em decorrência de sua natureza de direitos mínimos fundamentais ou de prerrogativas advindas do direito internacional dos direitos humanos (GUERRA; TONETTO, 2018).

O Brasil assinou a referida Convenção, a qual veio para reforçar as legislações e programas nacionais já existentes sobre os direitos das pessoas idosas, a exemplo da Política Nacional do Idoso, do Programa Nacional dos Direitos Humanos (PNDH-3), do Compromisso Nacional para o Envelhecimento Ativo e do Estatuto, bem como, contribui para reforçar as ações desenvolvidas no âmbito do Conselho Nacional dos Direitos do Idoso (CNDI). Impende ressaltar que, o Brasil, por meio da lei n 16.646, de 9 de abril de 2018, instituiu o ano de 2018 como o "Ano da Valorização e Defesa dos Direitos Humanos da Pessoa Idosa", isso ressalta a importância da presente Convenção (BRASIL, 2017).

A Convenção tratou de diversas normas que tutelam o idoso, mas deixou amplamente expresso o direito à saúde, no artigo 19, o qual transcreve-se, literalmente, o seu texto:

Os Estados Partes deverão formular e implementar políticas públicas intersetoriais de saúde orientadas a uma atenção integral que inclua a promoção da saúde, a prevenção e a atenção à doença em todas as etapas, e a reabilitação e os cuidados paliativos do idoso, a fim de propiciar o desfrute do mais alto nível de bem-estar fisco, mental e social. Para tornar efetivo este direito, os Estados Partes se comprometem a tomar as seguintes medidas:[...] letra b: formular, implementar, fortalecer e avaliar políticas públicas, planos e estratégias para fomentar um envelhecimento ativo e saudável[...] letra d: fortalecer as ações de prevenção por meio das autoridades da saúde e a prevenção de doenças [...] letra h:inclusive as enfermidades crônicas degenerativas, as demências e a doença de Alzheimer [...] (ORGANIZAÇÃO DOS ESTADOS AMERICANOS, 2015).

Os direitos da personalidade remetem a valores imprescindíveis como a vida e a integridade psicofísica, desse modo, se colocados numa organização hierárquica, ocuparão o mais alto nível desta (BARLETTA, 2016). O caminho para reconhecer os idosos como sujeitos com direitos é o que garante sua inclusão em uma sociedade integrada. Nessa esteira de pensamento, a Convenção representa um conjunto de medidas cujo objetivo principal é oportunizar maior visibilidade internacional à pessoa idosa. Evidencia-se, portanto, claramente a necessidade de se buscar políticas adequadas que respondam aos desafios atuais, oriundos do envelhecimento populacional (OCA et al., 2019).

A Convenção constitui um passo relevante no reconhecimento dos direitos dos idosos, mas deve, após a ratificação do Congresso Nacional, vir acompanhada de medidas concretas para lograr êxito em relação à efetiva realização dos direitos nela reconhecidos. Será necessário um esforço significativo por parte do poder público para instrumentalizar as suas instituições objetivando oferecer tratamento adequado e preferencial às questões relativas aos idosos. (GOLDFARB, 2016).

Investigue-se, não obstante, que a Constituição Federal de 1988 em seu artigo $1^{\circ}$, inciso III, estabelece, ao considerar a dignidade humana como valor sobre o qual se fundamenta a República, uma cláusula geral, a qual tutela todos os direitos da personalidade. Dessa forma, no ordenamento pátrio, o princípio da dignidade da pessoa humana "atua como uma cláusula geral de tutela e promoção da personalidade em suas mais diversas manifestações que, 
portanto, não pode ser limitada em sua aplicação pelo legislador ordinário" (MORAES, 2008, p. 6).

Frise-se a importância do artigo $1^{\circ}$ inciso III da Constituição Federal de 1988, Estabeleceu a dignidade humana como princípio fundamental. E ainda, em relação específica à tutela dos idosos, resgata-se o artigo 196 da Carta Magna, o qual, estabelece que

[...] a saúde é direito de todos e dever do Estado, garantido mediante políticas sociais e econômicas que visem à redução do risco de doença e de outros agravos e ao acesso universal e igualitário às ações e serviços para sua promoção, proteção e recuperação (BRASIL, 1988).

Destaque-se que a Convenção Interamericana sobre a Proteção dos Direitos Humanos dos Idosos, de 2015, a qual o Brasil assinou,encontra-se aprovada no âmbito da Câmara Federal e continuará seu trâmite legal até ser incorporada amplamente no ordenamento jurídico brasileiro. Percebe-se que, nesse documento, há diversos direitos, que tutelam a saúde do idoso, especialmente no que tange ao aspecto psíquico, prevenindo doenças mentais e diminuindo o número de suicídios.

\section{SAÚDE DOS IDOSOS: POLÍTICAS PÚBLICAS BRASILEIRAS FRENTE À CONCLAMAÇÃO DA OMS}

Um dos grandes desafios do século atual é a implementação de políticas públicas que visem diminuir o número de casos de depressão relativos à terceira idade. No Brasil, a situação não é diferente. Tal assunto engloba a saúde pública e é de extrema seriedade e intensa prioridade a fim de ser combatido. Conforme já salientado, constatou-se que a OMS divulgou alto número de suicídios no mundo, considerando que esses ocorrem em todas as faixas etárias. Porém, o número de suicídios entre os idosos, tem crescido no Brasil, merecendo atenção.

Segundo o Relatório da Organização Mundial de Saúde sobre Violência e Saúde, realizado em Genebra, em 2002, a nível global, constatou-se uma média de 800 mil suicídios por ano, revelando um problema mundial de saúde, destacando a urgência do assunto. Nesse sentido, faz-se necessário que a implementação e a efetivação de políticas púbicas que tentem coibir ou diminuir esse quadro (ORGANIZAÇÃO MUNDIAL DA SAÚDE, 2010).

Os índices de suicídio não se apresentam igualmente em toda a população. Um marcador populacional importante para o risco de suicídio é a idade. No mundo todo, os índices de suicídio tendem a aumentar com a idade, embora alguns países, tenham recentemente apresentado um pico secundário entre pessoas jovens. No geral, os índices de suicídio entre pessoas acima de 70 anos são, aproximadamente, três vezes mais elevados do que entre pessoas mais jovens (MACIEL, 2017).

As mortes por suicídio referem-se apenas a uma parte desse grave problema. "Muitos ao realizar a tentativa efetivamente morrem, outros, porém, conseguem sobreviver aos atentados contra a própria vida. Todavia, as tentativas de ferir-se, que por si só, exigem bastante cuidados médicos". O comportamento suicida vai desde, simplesmente, pensar em 
exterminar a vida até "o desenvolvimento de um plano para cometê-lo, conseguir os meios de realizá-lo, ou seja, tentando se matar até finalmente realizar o ato 'suicídio completado'. Enfim, o termo 'suicídio' traz, em si, uma referência direta à violência e à agressividade" (ORGANIZAÇÃO MUNDIAL DA SAÚDE, 2002).

As mortes por suicídio referem-se apenas a uma parte desse grave problema. "Muitos ao realizar a tentativa efetivamente morrem, outros, porém, conseguem sobreviver aos atentados contra a própria vida. Todavia, as tentativas de ferir-se por si só, exigem bastante cuidados médicos". O comportamento suicida vai desde, simplesmente, pensar em exterminar a vida até "o desenvolvimento de um plano para cometê-lo, conseguir os meios de realizá-lo, ou seja, tentando se matar até finalmente realizar o ato 'suicídio completado'. Enfim, o termo 'suicídio' traz, em si, uma referência direta à violência e à agressividade" (ORGANIZAÇÃO MUNDIAL DA SAÚDE, 2002).

Desde 2003, o dia 10 de setembro foi instituído como o "Dia Mundial da Prevenção ao Suicídio pela Associação Internacional para a Prevenção do Suicídio e pela OMS (ORGANIZAÇÃO MUNDIAL DA SAÚDE, 2002). No dia $1^{\circ}$ de outubro de 2017, comemorou-se o "Dia Internacional da Pessoa Idosa", sendo que, a OMS conclamou por políticas públicas mundiais de atendimento mais efetivo para os sexagenários. Destacou-se que, até 2050, o número de pessoas idosas atingirá 2 bilhões. A referida organização internacional criticou os sistemas de saúde do mundo, os quais, na sua concepção, não estão aptos para atender essa população específica. Lembrou também que, os idosos são mais propensos a ter problemas crônicos de saúde e, muitas vezes, múltiplos concomitantemente. Contudo, os atuais sistemas de saúde, geralmente, se concentram no tratamento de doenças agudas individuais. Dessa forma, a articulação das diferentes áreas da saúde, ainda, é um desafio no atendimento aos idosos (ORGANIZAÇÃO DAS NAÇÕES UNIDAS, 2019).

Uma das diretrizes pontuais da OMS é o documento Guidelines on Integrated Care for Older People, o qual visa aprimorar o atendimento por meio de iniciativas como planejamento, avaliação integral dos pacientes e melhorar a integração dos setores que cuidam dos sexagenários. Segundo o organismo internacional, alguns países já adotaram estratégias, que vão ao encontro das recomendações da referida organização. É o caso do Brasil, que implementou algumas modificações nos serviços com os idosos (ORGANIZAÇÃO MUNDIAL DA SAÚDE, 2017).

A Organização Pan-Americana da Saúde lembra, ainda, que a OMS está desenvolvendo uma Estratégia Global e um Plano de Ação sobre Envelhecimento e Saúde. Ela será elaborada e aprovada em consulta com os Estados-membros. Já foram estabelecidas como ações prioritárias, a criação de ambientes age-friendly e melhorias no monitoramento e adaptação dos sistemas de saúde às necessidades eao bem-estar dos sexagenários (ORGANIZAÇÃO PAN-AMERICANA DA SAÚDE, 2019).

O aumento no número de suicídios inquieta, cada vez mais a OMS e outros órgãos internacionais. Dessa forma, a saúde mental é um dos alvos a ser alcançado nos "Objetivos de Desenvolvimento Sustentável, especificamente na "meta 3.4" até 2030, cujo fim é reduzir em um terço a mortalidade prematura por doenças crônicas não transmissíveis via prevenção, tratamento e promoção da saúde mental e do bem-estar". Firmou-se, a partir desse raciocínio, o entendimento que "o suicídio é um indicador de mortes evitáveis e isso mostra o 
comprometimento dos países em trabalhar cada vez mais esse tema" (ORGANIZAÇÃO PAN-AMERICANA DA SAÚDE, 2017).

Nesse sentido, a importância de uma estratégia global de atenção à saúde do idoso é observada, além do mais, é fundamental o envolvimento e a participação dos países na identificação das situações de risco, as quais contribuem para o aumento do número de suicídios, objetivando a sua prevenção. Por isso, uma das preocupações da OMS é que, os Estados-membros implementem políticas públicas, que contribuam para melhorar a qualidade de vida dos sexagenários, focando, principalmente, na saúde mental.

Conforme as estatísticas da OMS, o Brasil está em quinta posição no mundo e em primeiro lugar no ranking latino-americano da depressão. Ademais, os números de suicídios tendem a aumentar, proporcionalmente, às taxas de ansiedade e depressão. A advertência da referida OMS é que "a cada 45 minutos há um suicídio no Brasil, ou seja, 32 pessoas se suicidam por dia no país. A cada 40 segundos há um suicídio no mundo e que a cada 3 segundos há uma tentativa de suicídio" (FEDERAÇÃO DOS HOSPITAIS, CLÍNICAS, CASAS DE SAÚDE, LABORATÓRIOS DE PESQUISAS E ANÁLISES CLÍNICAS E DEMAIS ESTABELECIMENTOS DE SERVIÇOS DE SAÚDE DO ESTADO DE SÃO PAULO, 2017).

Contudo, há de se destacar, no Brasil, o trabalho do Ministério dos Direitos Humanos. Como exemplo, cita-se que, a partir de 2015, o Centro de Valorização da Vida (CVV) Conselho Federal de Medicina e a Associação Brasileira de Psiquiatria realizaram a campanha "Setembro amarelo", conclamando a sociedade a participar da prevenção ao suicídio. Entre as diversas diretrizes, houve a disponibilização para todo o Brasil de um canal de acesso telefônico, pelo Centro de Valorização da Vida, juntamente com o Ministério da Saúde. 0 atendimento é desenvolvido por voluntários e a ligação é gratuita para o número 188 (BRASIL, 2019).

Em 2017, o Ministério da Saúde divulgou o primeiro Boletim Epidemiológico de Tentativas e Óbitos por Suicídio no Brasil. A partir deste, comprovou-se que é alta a taxa de suicídio entre idosos com mais de 70 anos. Nessa faixa etária, foram registradas a média de 8,9 mortes por 100 mil, nos últimos seis anos. A média nacional é de 5,5 por 100 mil. Tal diagnósticoforneceuuma nova direção na assistência em saúde mental da nação. Constatou-se também que, o risco de suicídio reduz em até $14 \%$, nos locais onde existem Centros de Apoio Psicossocial (CAPS), os quais, foram uma iniciativa do Sistema único de Saúde (SUS), sendo que, o diagnóstico inédito orienta a expansão e qualificação da assistência em saúde mental no país. O Ministério da Saúde, com base nos dados do boletim, lança uma agenda estratégica para atingir meta da OMS de redução de 10\% dos óbitos por suicídio até 2020 . Entre as ações, destacam-se a capacitação de profissionais, orientação para a população e jornalistas, a expansão da rede de assistência em saúde mental nas áreas de maior risco e o monitoramento anual dos casos no país e a criação de um Plano Nacional de Prevenção do Suicídio (MACIEL, 2017).

Estima-se que, nos próximos 20 anos, a depressão se tornará a doença mais conhecida no mundo, prejudicando mais pessoas do que qualquer outro problema de saúde e será a que mais trará despesas para os governos por causa dos gastos com o tratamento dos pacientes. Os países mais pobres são os que mais são avassalados pelo problema. No Brasil, 23 milhões de pessoas necessitam de tratamento mental. As doenças mais graves estão ligadas à depressão e ansiedade (MENDES, 2013). 
Os idosos ocupam posição de destaque, necessitando atenção especial, principalmente, em relaçãoà saúde mental. Um dos grandes desafios da política pública é identificar os fatores, que envolvem o risco de suicídio, especialmente entre os sexagenários, a fim de desenvolver uma política nacional de prevenção e combate. Analisando um perfil em relação aos fatores de risco, que envolvem o suicídio, há "os transtornos mentais, como depressão, alcoolismo, esquizofrenia; questões sócio demográficas, como isolamento social; psicológicos, como perdas recentes, e, condições clínicas incapacitantes, como lesões, dor crônica, neoplasias malignas" (BRASIL, 2017).

$\mathrm{Na}$ idade senil, quando há perda de laços referenciais, o idoso fica mais vulnerável. Em média, o jovem faz 20 tentativas para um efeito, o suicídio. No idoso, são quatro tentativas. Muitas vezes, não há tentativa, é única. Eles usam métodos definitivos. De acordo com o Ministério da Saúde, na faixa etária dos 75 anos, ocorrem de oito a 12 suicídios masculinos por um feminino. A depressão tem grande influência. Verifica-se que, por trás do desejo de antecipar o fim da vida, estão as questões relativas à terceira idade, as perdas de saúde, autonomia, produtividade, não se sentir mais útil, etc. Ressalta-se, ainda, que, a aposentadoria faz o idoso ficar mais tempo dentro de casa, prejudicando os relacionamentos sociais e aumentando o isolamento (OLIVETO, 2019).

Desde 2015, o CVV, em parceria com o Conselho Federal de Medicina e a Associação Brasileira de Psiquiatria lançaram a campanha "Setembro amarelo", convocando cada brasileiro a apoiar e participar da prevenção ao suicídio. Foi disponibilizado para todo o país, um canal de acesso telefônico, o 188, pelo Centro de Valorização da Vida, em parceria com o Ministério da Saúde. A ligação é gratuita e a importância de pessoas depressivas terem acesso a esse canal, é fundamental, pois a estratégia é acolher e compreender a dor dos que se encontram em depressão. Ouvir, pode ser mais importante do que orientar, por isso, investir tempo nesse canal de atendimento possibilita a construção de vínculos, que auxiliam na reabilitação. Na realidade, o tema suicídio deve ser concebido como uma questão de saúde pública, que depende da mobilização de todos os brasileiros. Essas e outras diretrizes fundamentam a política nacional de combate ao suicídio e, principalmente, de ações do Ministério de Direitos Humanos para promoção da proteção e dos direitos dos idosos (BRASIL, 2018).

Atualmente, a lei no 13.819 de 2019 instituiu a Política Nacional de Prevenção da Automutilação e do Suicídio no Brasil. Tal lei prevê notificação compulsória, que deverá ser sigilosa e será utilizada para os casos, que apresentarem tentativa de suicídio e automutilação. "Incluiu a criação de um sistema nacional, envolvendo estados, municípios, prevenindo a automutilação e suicídio, bem como um serviço telefônico gratuito para atendimento ao público" (BRASIL, 2019).

A referida política é uma importante ferramenta para compreender a origem dos problemas relacionados a perda de tantas vidas. Objetivou-se através do estudo, criar políticas mais apropriadas para contribuir na melhoria dessa situação. Até pouco tempo, esse problema era tratado como tabu e muitos não queriam tocar no assunto, optava-se pelo silêncio, acreditando que evitaria estímulo a novos casos (BRASIL, 2019). Porém, hoje, os estudiosos destacam a importância da informação a respeito deste delicado tema.

No Brasil, o Estatuto contribuíu para a garantia da tutela do idoso brasileiro, regulando os direitos assegurados às pessoas a partir dos sessenta anos. Convém destacar que, o Estatuto estabelece as oportunidades e facilidades atribuídas à pessoa idosa e constam 
como direitos fundamentais, portanto, como alicerces em que se edifica sua proteção integral (BARLETA, 2016).

Atualmente, tem crescido a demanda por serviços de atendimentos especializados para os sexagenários. No Brasil, surgiram as Instituições de Longa Permanência, os Centros de Convivência e os Centros-Dia para idosos. Os primeiros oferecem domicílio coletivo para os senis em situação de vulnerabilidade. Os segundos oferecem atividades de cultura e lazer aos que possuem autonomia, independência. Os terceiros se caracterizam como um espaço para atender idosos que possuem algumas limitações para a realização das atividades diárias, mas não comprometimento severo, na maioria das vezes, residem com suas famílias, mas não dispõem de atendimento em tempo integral em seus domicílios, é um serviço destinado às atividades diurnas (FREITAS, 2019).

Na maioria das vezes, não é tarefa fácil, mas é possível buscar opções de convivência, como aulas, academias, vizinhança e outros espaços sociais. Não olvidando que é comum ao passar dos anos reduzir as redes de relações sociais (VALADARES, 2019). Ressalte-se a importância dos idosos em manterem suas amizades, além da família pois, a convivência social evita o isolamento e é fundamental para ajudar a evitar a depressão.

Impende ressaltar que o objetivo do Centro Dia, deve incluir não apenas a proteção, mas a melhoria da qualidade de vida e a autonomia do idoso, favorecendo também as condições de vida dos familiares que passam a ter auxílio no cuidado de seus parentes, sem que isto represente a perda de vínculos. Ao conviver com outras pessoas, eles fazem atividades para passar o tempo de forma prazerosa e construtiva, além de construir e aumentar vínculos sociais e afetivos. Nos municípios que possuem as Instituições de Centros Dia para sexagenários, o encaminhamento para esse serviço é realizado através dos Centros de Referência Especializados da Assistência Social (CREAS), relacionados às respectivas Secretarias Municipais de Assistência Social. O problema é que nem sempre há vagas disponíveis para demanda. Urge investimentos públicos para aumentar a oferta destas nos municípios, pois, muitos idosos ficam excluídos desta assistência social que é extremamente salutar. (FREITAS, 2019).

Ante aos dados revelados, a OMS conclama os Estados-membros para o bem-estar social, considerando a saúde psicofísica dos idosos e suscita que os mesmos desenvolvam políticas públicas adequadas a solucionar ou o problema suscitado. O Brasil dispõe de algumas políticas públicas direcionadas nessa área, conforme ficou evidenciado, porém, ainda há muito por fazer pela pessoa idosa para que a mesma seja tutelada nas suas necessidades e sua dignidade seja respeitada.

\section{CONCLUSÃO}

Enfatizou-se no decorrer do presente trabalho que há uma pertinente preocupação da OMS e da OEA direcionada ao novo quadro demográfico mundial, visto o crescente número de pessoas idosas. Por conseguinte, ocorre o surgimento de novas demandas para atender as necessidades desse público, especialmente, ao que se refere à saúde integral e o bem estar social da pessoa idosa. 
Quanto ao Brasil, evidenciou-se que na literatura jurídica já havia, previamente, um anseio para atender e proteger a terceira idade. Note-se, a saber, o Estatuto que regula os direitos assegurados a esse grupo vulnerável. Observou-se que falar sobre suicídio, até pouco tempo era considerado um imenso tabu. Porém, atualmente, devido às atuais políticas públicas, esse tema, passou a ser amplamente debatido pela sociedade e também através do Centro de Valorização da Vida (CVV), Ministério da Saúde e do Conselho Nacional de Medicina.

A partir da análise dos aportes teóricos como o Estatuto, a Convenção, sites jurídicos nacionais, internacionais e governamentais pertinentes à pesquisa, bem como, sites especializados de sindicato de hospitais, de psicologia, de enfermagem; revistas jurídicas e jornais; Ministério de Direitos Humanos e Família verificou-se várias políticas públicas brasileiras que corroboram para a melhoria da situação apresentada e se sobressaíram nesse artigo quatro delas. A primeira, é o canal de acesso telefônico, pelo CVV, juntamente com o Ministério da Saúde. A segunda, refere-se a importância do trabalho dos Centros de Apoio Psicossocial (CAPS) reduzindo o risco de suicídio nos locais disponíveis. A terceira, é a lei nº 13.819 de 2019 direcionada à Política Nacional de Prevenção da Automutilação e do Suicídio no Brasil. Ela prevê a notificação compulsória que deverá ser sigilosa para os casos que apresentarem tentativa de suicídio e automutilação. Dessa forma, os dados levantados formam uma importante ferramenta para compreender as causas desse problema.

A quarta política, enfatiza as Instituições de Longa Permanência, os Centros de Convivência e os Centros-Dia, espaços de convivência social com atendimento especializado para atender as necessidades do idoso com opções de convivência, lazer e participação social. Faz-se indispensável investimentos para ampliação e para a disponibilização desse serviço em todo o território nacional. Esses são exemplos de políticas públicas brasileiras que têm contribuído na melhoria e na qualidade de vida de muitos idosos brasileiros, corroborando para diminuir as doenças mentais como a depressão e o risco de suicídio.

Nessa seara, o Brasil em 2015 assinou a Convenção Interamericana sobre a Proteção dos Direitos Humanos dos Idosos, documento juridicamente vinculante aos Estados Partes. Ela deverá ser incorporada ao ordenamento jurídico pátrio e contribuirá efetivamente com a proteção do idoso, principalmente no que se refere a saúde mental. Tal análise partiu da interpretação devidamente expressa no artigo 19 do referido diploma. Apesar das legislações nacionais que protegem o idoso brasileiro, esse documento colaborará intensamente com a saúde e o bem-estar social do idoso ao ser incorporada no ordenamento jurídico brasileiro, especialmente em relação à saúde psicofísica da pessoa idosa.

Constatou-se após a revisão bibliográfica que, atualmente, a discriminação, a falta de condições econômicas, o abandono e a violência cometida contra o indivíduo idoso, consideradas como violação aos direitos humanos e, essencialmente, a falta de políticas públicas adequadas para a prevenção de saúde mental do idoso no Brasil, carecem de particular atenção por parte dos gestores públicos. Diante dessa realidade, apurou-se que há urgência na articulação entre família, sociedade civil e o poder público para minimizar o índice de suicídios entre idosos. Verificou-se que há muito ainda por fazer a favor desse grupo vulnerável.

Por todo o exposto, é fundamental que a sociedade e o poder público prestem mais atenção à vulnerabilidade da pessoa idosa e implementem políticas públicas eficientes e adequadas, direcionadas, particularmente, ao seu aspecto mental e emocional. Nesse viés, deve ocorrer um engajamento por parte da sociedade, pois, é imprescindível que o idoso 
como elemento integrante de um grupo vulnerável, tenha assegurado amplamente os seus direitos de personalidade e respeitada a sua dignidade.

\section{REFERÊNCIAS}

ALENCAR, Evandro Luan de Mattos; RAIOL, Raimundo Wilson Gama. Uma análise do caso Ximenes Lopes versus Brasil: o debate sobre políticas públicas, Saúde mental e direitos humanos no Sistema interamericano de direitos Humanos. Revista Direito e Justiça: Reflexões Sociojurídicas. Santo Ângelo. V. 20, n. 36, p. 129-155, 2020. Disponível em: http://srvapp2s.urisan.tche.br/seer/index.php/direito_e_justica/article/view/2982/0. Acesso em: 15 ago. 2020.

BARLETTA, Fabiana Rodrigues. O direito à saúde da pessoa idosa. São Paulo: Saraiva, 2016.

BRASIL Ministério de Direitos Humanos. Sancionada a Política Nacional de Prevenção da Automutilação e do Suicídio. 2019. Disponível em: https://www.mdh.gov.br/todas-as-noticias/2019/abril/sancionada-a-politica-nacional-de-prevencao-da-automutilacao-e-do-suicidio. Acesso em: 14 ago. 2020.

BRASIL. Câmara dos Deputados. Projeto de decreto legislativo 863/2017. Disponível em: https://www.camara.leg. br/proposicoesWebprop_mostrarintegra?codteor=1629742\&filenamePDC+863/2017. Acesso em: 15 ago. 2020.

BRASIL. Código Penal. Decreto-Lei no 2.848, de 7 de dezembro de 1940. Disponível em: http://legislacao.planalto. gov.br/legisla/legislacao.nsf/Viw_Identificacao/DEL\%202.8481940?OpenDocument. Acesso em: 15 ago. 2020.

BRASIL. Constituição 1988. Constituição da República Federativa do Brasil de 1988. Brasília, DF: Presidência da República, 2020. Diponível em: http://www.planalto.gov.br/ccivil_03/constituicao/constituicao.htm. Acesso em: 16 ago. 2020.

BRASIL. Governo Federal. MDH alerta para Dia Mundial de Prevenção ao Suicídio e cita pessoas idosas. Disponível em: https://www.mdh.gov.br/todas-as-noticias/2018/setembro/mdh-alerta-para-dia-mundial-de-prevencao-ao-suicidio-e-cita-pessoas-idosas. Acesso em: 19 ago. 2020.

BRASIL. Lei 10.741/2003. Estatuto do Idoso. Disponível em: http://www.planalto.gov.br/ccivil_03/leis/2003/ 110.741.htm. Acesso em: 18 ago. 2020.

BRASIL. Lei 13.819/2019. Política Nacional de Prevenção da Automutilação e do Suicídio. Disponível em: http:// www.planalto.gov.br/ccivil_03/_ato2019-2022/2019/lei/L13819.htm. Acesso em: 12 ago. 2019.

BRASIL. Ministério da Saúde. Violência intrafamiliar: orientações para prática em serviço. Secretaria de Políticas de Saúde, Brasília, DF: Ministério da Saúde, 2001.

BRASIL. Ministério de Direitos Humanos. MDH alerta para Dia Mundial de Prevenção ao Suicídio e cita pessoas idosas. 2018. Disponível em: https://www.mdh.gov.br/todas-as-noticias/2018/ setembro/mdh-alerta-para-dia-mundial-de-prevencao-ao-suicidio-e-cita-pessoas-idosas. Acesso em: 12 ago. 2020.

BRASIL. Secretaria de Direitos Humanos da Presidência da República. Brasil: manual de enfrentamento à violência contra a pessoa idosa. É possível prevenir. É necessário superar. Brasília, DF: Secretaria de Direitos Humanos da Presidência da República, 2014.

FEDERAÇÃO DOS HOSPITAIS, CLÍNICAS, CASAS DE SAÚDE, LABORATÓRIOS DE PESQUISAS E ANÁLISES CLÍNICAS E DEMAIS ESTABELECIMENTOS DE SERVIÇOS DE SAÚDE DO ESTADO DE SÃO PAULO. Brasil lidera ranking de depressão e suicídio na América Latina. Disponível em: https://fehoesp360. 360.org.br/sindhop. Acesso em: 15 ago. 2020.

FREITAS, Raquel; RIBAS, Fabio. Centro Dia do Idoso: espaço de proteção e cuidado. Disponível em: http://prattein. com.br/home/index.php?option=com_content\&view=article\&id=855:centro-dia-do-idoso-espaco-de-protecao-e-cuidado\&catid=100:programas-de-atencao-ao-idoso\&Itemid=190. Acesso em: 19 ago. 2020. 
GOLDFARB, Maurício. Los adultos mayores como sujetos vulnerables (a propósito de la Convención Interamericana sobre la Protección de los Derechos Humanos de las Personas Mayores). Disponível em: http://repositorio.unne.edu.ar/bitstream/handle/123456789/9055/RIUNNE_AR_Goldfarb_M_10.pdf?sequence=1\&isAllowed=y . Acesso em: 17 ago. 2020.

GUERRA, Sidney; TONETTO, Fernanda Figueira. O direito de ação como instrumento de tutela dos direitos humanos. Revista Direito e Justiça: Reflexões Sociojurídicas. Santo Ângelo, v. 18, n. 31, p. 85-102, 2018. Disponível em: http://srvapp2s.santoangelo.uri.br/seer/index.php/direito_e_justica/article/view/2685. Acesso em: 26 fev. 2020. https://digital.csic.es/bitstream/10261/196077/3/Older_Persons_Human_Rigths.pdf. Acesso em: 16 ago. 2020 INTITUTO BRASILEIRO DE GEOGRAFIA E ESTATÍSTICA. Idosos indicam caminhos para uma melhor idade. 19 março 2019. Disponível em: https://censo2020.ibge.gov.br/2012-agencia-de-noticias/noticias/24036-idosos-indicam-caminhos-para-uma-melhor-idade.html. Acesso em: 17 ago. 2020.

JUSTO, José Sterza; ROZENDO, Adriano da Silva. A velhice no Estatuto do Idoso. Periódicos Eletrônicos em Psicologia. Rio de Janeiro n. 2, p. 471-489, $2^{\circ}$ quadrimestre de 2010. Disponível em: http://pepsic.bvsalud.org/scielo. php?script=sci_abstract\&pid=S1808-42812010000200012\&lng=pt\&nrm=iso. Acesso em: 10 Ago. 2020.

MACIEL, Victor. Taxa de suicídio é maior em idosos com mais de 70 anos. Ministério da Saúde, 21 Setembro 2017. Disponível em: http://www.saude.gov.br/noticias/agencia-saude/29691-taxa-de-suicidio-e-maior-em-idosos-com-mais-de-70-anos. Acesso em: 18 ago. 2020.

MENDES, Karyna Rocha. Curso de Direitos da Saúde. São Paulo: Saraiva, 2013.

MINAYO, Maria Cecília de Souza. Centro Latino-americano de Estudos sobre Violência e Saúde Jorge Careli. Inserção do tema violência contra a pessoa idosa nas políticas públicas de atenção à saúde no Brasil. Revista Ciência \& Saúde Coletiva, Rio de Janeiro, vol. 15, nº 2010.

MINAYO, Maria Cecília de Souza. Pesquisa Social: Teoria, método e criatividade. Editora Vozes, Petrópoles, 2010.

MORAES, Maria Celina Bodin. Ampliando os direitos da personalidade. In.: 20 anos da Constituição Cidadã de 1988: efetivação ou impasse institucional. Org.: José Ribas Vieira. Rio de Janeiro: Forense, 2008. Disponível em: https://www.academia.edu/9689598/Ampliando_os_direitos_da_personalidade. Acesso em: 18 ago. 2020.

OCA, Verônica Montes de et al. Older persons and human rights in Latin America and the Caribbean. 2018. Disponível em: https://digital.csic.es/bitstream/10261/196077/3/Older_Persons_Human_Rigths.pdf. Acesso em: Acesso em: 16 ago. 2020.

OLIVEIRA, Simone Camargo, et al. Violência em idosos após a aprovação do Estatuto do Idoso: revisão integrativa. Revista Eletrônica de Enfermagem. v.14, 2012. Disponível em: https://revistas.ufg.br/fen/article/view/12919. Acesso em: 18 ago. 2020.

OLIVETO, Paloma. Crescem os casos de suicídio entre idosos no Brasil. Correio Braziliense. Disponível em: https:// especiais.correiobraziliense.com.br/crescem-os-casos-de-suicidio-entre-idosos-no-brasil. Acesso em 16 ago. 2020.

ORGANIZAÇÃO DAS NAÇÕES UNIDAS BRASIL. A ONU e as pessoas idosas. Nações unidas Brasil. Disponível em: https://nacoesunidas.org/acao/pessoas-idosas/. Acesso em: 12 fev. 2020.

ORGANIZAÇÃO DAS NAÇÕES UNIDAS BRASIL. OMS cobra melhorias no atendimento aos idosos. Nações Unidas Brasil, 02 outubro 2017. Disponível em: https://nacoesunidas.org/oms-cobra-melhorias-no-atendimento-aos-idosos/. Acesso em: 18 ago. 2020.

ORGANIZAÇÃO DAS NAÇÕES UNIDAS. Plano de ação internacional contra o envelhecimento, 2002. Organização das Nações Unidas, tradução de Arlene Santos, Brasília: Secretaria Especial dos Direitos Humanos, 2003. Disponível em: http://www.observatorionacionaldoidoso.fiocruz.br/biblioteca/_manual/5.pdf. Acesso em: 17 ago. 2020.

ORGANIZAÇÃO DAS NAÇÕES UNIDAS. Plano de ação internacional sobre o envelhecimento, 2002. Tradução Arlene Santos. Brasília: Secretaria Especial dos Direitos Humanos, 2003. Título original: Plan de Acción Internacional de Madrid sobre el Envejecimiento, 2002. Disponível em: http://www.observatorionacionaldoidoso.fiocruz. br/biblioteca/_manual/5.pdf. Acesso em: 15 ago. 2020. 
ORGANIZAÇÃO DOS ESTADOS AMERICANOS. Convenção Interamericana sobre a Proteção dos Direitos Humanos dos Idosos de 2015. Disponível em: http://www.mpsp.mp.br/portal/page/portal/CAO_Idoso/Textos/Convenção\%20Interamericana.pdf. Acesso em:15 ago. 2020.

ORGANIZAÇÃO MUNDIAL DE SAÚDE. Relatório mundial sobre violência e saúde. Genebra (Suíça). Organização Mundial de Saúde, 2002. Disponível em: https://opas.org.br/wp-content/uploads/2015/09/relatorio-mundial-violencia-saude.pdf. Acesso em: 16 ago. 2020.

ORGANIZAÇÃO PAN-AMERICANA DA SAÚDE. No Dia Internacional da Pessoa Idosa, OPAS chama atenção para envelhecimento saudável. Disponível em: https://www.paho.org/bra/index.php?option=com_ content\&view=article\&id=5515:no-dia-internacional-da-pessoa-idosa-opas-chama-atencao-para-envelhecimento saudavel\&ltemid=820. Acesso em: 16 ago. 2020.

ORGANIZAÇÃO PAN-AMERICANA DA SAÚDE. Suicídio é grave problema de saúde pública e sua prevenção deve ser prioridade. Disponível em: https://www.paho.org/bra/index.php?option=com_content\&view=article\&id=56 74:suicidio-e-grave-problema-desaudepublicaesuaprevencaodeveserprioridadeafirmaopasoms\&ltemid=839. Acesso em: 18 ago. 2020.

REMÉDIO, José Antonio; FARIA, Cássio Henrique. Convenção da Apostila de Haia: Incorporação e Integração ao ordenamento jurídico nacional e interface com os direitos fundamentais. 2019. Revista Meritum, Belo Horizonte, v. 14, n. 2, p. 708-726, jul./dez. 2019. Disponível em: http://www.fumec.br/revistas/meritum/article/view/7050. Acesso em: 18 ago. 2020.

RIO DE JANEIRO. Tribunal de Justiça. Apelação Criminal nº 0201897.91.2011.8.19.0001 - 38a Vara Criminal. Apelante: Ministerio Público. Apelada: Elisangela Rodrigues da Silva. Relatora Juíza Marcia Perrini Bodart, Rio de Janeiro, julgamento em 19 de Fevereiro de 2013. Disponível em: https://tj-rj.jusbrasil.com.br/jurisprudencia/385389540/apelacao-apl-2018979120118190001-rio-de-janeiro-capital-38-vara-criminal?ref=feed. Acesso em: 12 ago. 2020.

ROBINSON, Mary. O Marco legal internacional e nacional dos direitos da pessoa idosa. Disponível em: http://www. dhnet.org.br/dados/cursos/dh/cc/3/idoso/marco.htm. Acesso:15 ago. 2020.

SANTOS, Cristiano Lange dos; SCHMIDT, João Pedro. Juventude e suicídios: exame da política de prevenção do suicídio no município de Porto Alegre. 2019. Revista Meritum, Belo Horizonte, v. 14, n. 2, p. 238-260, jul./dez. 2019. Disponível em: http://www.fumec.br/revistas/meritum/article/view/7330. Acesso em: 19 ago. 2020.

UNITED NATIONS . Second World Assembly on Ageing. Political Declaration and Madrid Internacional plain of action on ageing. Madrid, Spain, 2002. Disponível em: https://www.un.org/en/events/pastevents/pdfs/Madrid_ plan.pdf. Acesso em: 16 ago. 2020

UNITED NATIONS. Department of Economic and Social Affairs, Population Division (2020). World Population Ageing 2019. Disponível em: https://www.un.org/development/desa/pd/sites/www.un.org.development.desa. pd/files/files/documents/2020/Jan/un_2019_worldpopulationageing_report.pdf. Acesso em: 15 ago. 2020.

UNIVERSIDADE DE SÃO PAULO. Em 2030, Brasil terá a quinta população mais idosa do mundo. Jornal da USP, 07 junho 2018. Disponível em: https://jornal.usp.br/atualidades/em-2030-brasil-tera-a-quinta-populacao-mais-idosa-omundo/. Acesso em: 14 ago. 2020.

VALADARES, Carolina. Convivência social ajuda a prevenir depressão entre os idosos. Disponível em: http:// www. blog.saude.gov.br/ index.php/promocao-da-saude/53632- convivencia-social-ajuda-prevenir-depressao-entre-os-idosos. Acesso em: 13 ago. 2020.

VIOLÊNCIA contra o idoso provoca desejo de suicídio. Diário da Manhã. Goiânia /GO, 05 de julho de 2016. Disponível em: https://www.dm.jor.br/cotidiano/2016/07/violencia-contra-o-idoso-provoca-desejo-de-suicidio/. Acesso em: 14 ago. 2020.

Recebido/Received: 22.06.2020.

Aprovado/Approved: 26.09.2020. 